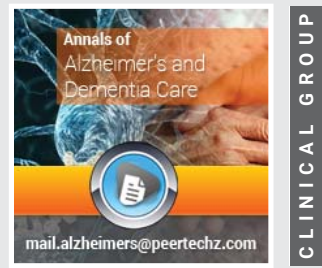

\title{
The role of gender and
}

\section{personality (Type "A" and}

\section{"B"); on emotional stressful}

\section{experience}

\section{Ofojebe Chukwuma Philip, Okoli Paul Chibuike* and Okpala Micheal Okemefuna}

College of Medicine, Nnamdi Azikiwe University, Along Enugu-Onitsha Expressway, Ifite Road, 420110 Awka, Nigeria
Received: 19 September, 2019

Accepted: 24 December, 2019

Published: 26 December, 2019

*Corresponding author: Okoli Paul Chibuike, PhD, College of Medicine, Nnamdi Azikiwe University, Along Enugu-Onitsha Expressway, Ifite Road, 420110, Awka, Nigeria, Tel: 8037110292;

E-mail: okolipd71@gmail.com

https://www.peertechz.com

Check for updates

\section{Abstract \\ Background: Stress is not merely something that makes one worry. It is rather ubiquitous. It is synonymous with life. We live in an age of great stress and anxiety and it impacts more on our life and social wellbeing depending on one's gender and personality types.}

Aim: To increase our knowledge of the role of stress in human life, social, and physical wellbeing and to create awareness on the harmful effect of the clinical condition of stress.

Setting: The study was carried out teachers in 18 public Secondary schools in Aguata and Anaocha Local Government Councils of Anambra State Nigeria.

Method: This was a cross-sectional and descriptive study of 90 secondary school teachers using Jenkins Activity Survey Scale (Jas), Symptom Distress Checklist (Scl-90) and a sociodemographic questionnaire.

Results: On the role of gender and personality types on emotional stressful experience, a personality has the highest mean of 120.24 ; while type B personality has the total mean of 96.96 while on gender scale, the females have the mean of 109.67 and males have the mean of 107.13.

Conclusion: Personality Type as a factor yielded a significant effect in manifestation of emotional stress. Gender however did not significantly affect manifestation of emotional stress. On the other hand it was shown that there is interactive effect between gender and personality type in emotional stress reaction to noxious life experiences.

\section{Introduction}

We live in an age of great stress and anxiety, which impact on our life and social wellbeing. There are feelings of uncertainty, insecurity, helplessness and frustration that are generated by the daily news of inflation, kidnapping, herds men attacks, unemployment, tribal wars and poverty, high cost of goods and services among other things. According to Nweze [1], our desire to beat deadlines, to do much in the shortest possible time, failures and other tragic life experiences, also trigger psychological disturbances often manifested in stress reactions, to the extent that our physical and emotional wellbeing are threatened.
Stress is not merely something that makes one worry. It is rather ubiquitous. It is synonymous with life. We experience stress in almost all we do: happy things, sad things, spiritual things, and physical things. As regard human body, stress is synonymous with physiological changes. Anything that causes a change in your life causes stress. Even imagined change (such as the worry that you may get fired or that you may receive promotion at work) is a source of stress.

However, some stress can very pleasant or curative and is known as eustress. This is often controlled which gives individual competitive edge in performance related activities such as publish speech presentation, athletics, and etc. This can be distinguished from negative stress (when something 
changes for the better) [positive stress] and distress (when something changes for worse) negative stress. On the other hand negative is one that beyond the individual's ability to cope. However, some considers stress to include anxiety, and fear for what may happen. In clinical research, however, stress is a disrupter of human skill and performance. It is a process of transaction between the individual and the environment in which the resources of individual are matched against the demand of the environment.

It is in this light that Nweze [1], maintained that "stress as an emotional experience can be a momentary affair. In such cases, the social antecedents of stress (psychosocial stressors) are short-lived and we may possess the psychological resources to cope and go through the situations without undue disruption of adaptive responses. When this is the case, stress possesses an energizing effect that affects human motivation, thus acting as a signal for us to get ready for action. Conversely, an emotional experience can become longstanding because we either do not possess the psychological wherewithal to deal with it or we are incapable of remedying the stressful situations. In such cases the deleterious effects of stress not only affect our health and well-being but diminish our productivity".

Isichei [2], reiterating Nweze [1], idea, maintained that three psychological substrates underscore stress. The substrates are

1. Conflict: It arises when there is a set of alternatives from which one is to make a choice.

2. Frustration: One experiences frustration when one is unable to attain one's set goal and objectives.

3. Pressure: Pressure is precipitated by the urgency and immediate demands on one to take decisions that will lead to shifts in behaviour (adaptation).

These substrates place on the individual demands for adjustment and undue physiological reactions which if prolonged, could be detrimental to health.

Stress is equally defined as emotional experience which could be momentary, or long-term. Stress could as well be a state of being as well as a situation. As a state, it involves the disruption of a person's emotional homeostasis and the inducement of the disorganization of personality and behaviours. As a situation, stress is conceived as a reaction to environmental situation, provocation and or conditioning.

According to Oxford Dictionary of psychology Colman [3], stress was defined as "psychological and physical strain or tension generated by physical, emotional, social, economic or occupational circumstances, events or experiences that are difficult to manage or endure" [4], stress can be thought of in three ways:

1. As a stimulus (stressor). This is an external event that is threatening and potentially damaging [5]. Lazarus and Cohen [6], break such stressors into three categories: (1) cataclysmic, such as natural disasters or terrorist attacks; (2) personal, such as the death of a partner; and (3) daily hassles, which are more minor but also more persistent and frequent (e.g., having to get the children up, fed and to school on time).

2. As a response (strain). This is the feeling of nervousness that arises from having to attend an interview or give a speech, for example. The response involves emotional and cognitive components as well as physical reactions (e.g., rapid heartbeat or sweating). It may also have motivational elements, such as the apathy and loss of interest that accompany 'burn-out'.

3. As a process (transaction). The stressor and the strain have a different impact on a person depending on the characteristics of the person and the environment in which the stressor exists [7-9]. This approach takes into account the fact that the same external events will have different effects depending on the person experiencing them. This view is summed up neatly by Carroll [10]: 'Stress, like beauty, lies in the eye of the beholder'. It also views the person as an active agent who tries to cope with external demands using various strategies. Thus, the stress process has a cyclical aspect, as the person tries to cope with stressors, and reacts to the changing external situation. The process may sometimes run in a loop: a stressor poses a threat, which causes a feeling of strain or nervousness, which, if the person fails to cope adequately with the stressor, feeds back into further stress symptoms.

Stress is not necessarily seen as a stimulus or a response, but rather as a process. The person experiencing stress is an active agent who can influence the impact of a stressor through behavioural, cognitive and emotional shifts. In summary therefore, the word of Selye [11], who is a pioneer in stress research, still stands. He referred to stress as general adaptation Syndrome (GAS), which implies a state of stressful experience involving profuse non-specific physiological reactions to an emotional experience.

The impact of stress differs among individuals. Most stress research has focused on environmental correlates of stressful life experiences. Its expression is also linked up to that personality factors as an important part in the development of stress. Rahe, Mohan \& Arthur [12], had earlier in their study demonstrated that personality type affected reactions to negative events in one's life. In another context, the phenomenon of stress has generated great interest among clinicians and researchers. Actually, physicians have suspected for years that a certain lifestyle might be the basis of many instances of heart disease. In a book published by two cardiologists Friedman and Rosenman [13], entitled Type A behavior and Your Heart; two broad classification of personality types were presented as "Type A and Type B". This label of theirs has been generally accepted and popularized.

Their thesis was that a specific behavior pattern, called coronary-prone behaviour or Type A behaviour, may contribute more to heart disease than all the physical risk factors combined. The Type A behavior pattern stands for a coping style geared toward asserting and maintaining control over 
potentially irrepressible situations This is because control over all aspects of the environment is serious for these individuals, they must speed up the pace at which they live and work in order to sustain this mastery. Thus time always living on their nerves becomes essential aspect of their psychological makeup

Type B's have been characterized as calming personalities, naturally able to draw down stress in interpersonal transactions and organizations

Stress therefore, is a necessary part of life, but the impact has different effect, depending partly on individual personality traits [14].

One can then query: who is more prone to stress? What kind of personality is more prone to over responsiveness to stress? Would male and female, experience stress or its related problems at one time or the other? Are personality variables factors in stress reaction? People with certain personality types seem to be physiologically over responsive to stress and therefore more vulnerable to heart disease [15].

'Stress' is an important, but rather vague term. It may be defined as a stimulus (e.g., life events), as a response or outcome (e.g., autonomic arousal), or as a dynamic transaction between person and environment, supported by cognitions such as appraisal and coping. Personality factors may influence what kind of life events the person experiences, and how responsive the person is to stressful events. Traits may also bias appraisal and coping processes, influencing adaptation to demanding events. At a physiological level, stress is often related to Selye's 'General Adaptation System' [16], although this generalised stress response is now seen a s over-simplified. There are systematic individual differences in physiological reactivity, which may have a genetic basis. It remains to be seen how closely these physiological processes relate to personality [14].

When you perceive a threat, your nervous system responds by releasing a flood of stress hormones, including adrenaline and cortisol. These hormones rouse the body for emergency action.

Your heart pounds faster, muscles tighten, blood pressure rises, breath quickens, and your senses become sharper. These physical changes increase your strength and stamina, speed your reaction time, and enhance your focus - preparing you to either fight or flee from the danger at hand.

Stress is a normal physical response to events that make you feel threatened or upset your balance in some way. When you sense danger-whether it's real or imagined-the body's defenses kick into high gear in a rapid, automatic process known as the "fight-or-flight" reaction, or the stress response.

The stress response is the body's way of protecting you. When working properly, it helps you stay focused, energetic, and alert. In emergency situations, stress can save your lifegiving you extra strength to defend yourself, for example, or spurring you to slam on the brakes to avoid an accident.

The stress response also helps you rise to meet challenges.
Stress is what keeps you on your toes during a presentation at work, sharpens your concentration when you're attempting the game-winning free throw, or drives you to study for an exam when you'd rather be watching television.

But beyond a certain point, stress stops being helpful and starts causing major damage to your health, your mood, your productivity, your relationships, and your quality of life [17].

\section{Personality type}

In a general sense, a type is a group or category of things distinguished by the common characteristics of its members. A personality type, therefore, is a category of people who exhibit a particular combination of psychological characteristics, the assumption being that this combination is unique and distinguishes the type from others.

Since ancient times, there has been a great deal of speculation about types of people. One of the earliest, and most influential, personality typologies comes to us from ancient Greece where a number of scholars, such as Aristotle, Galen, and Hippocrates, contributed to the development of a typological theory of temperament based on the doctrine of "humors." The four humors (blood, black bile, yellow bile, phlegm) were seen as bodily substances that combined in various ways to produce four types of temperament. This is not quite as ridiculous as it might appear for, in modern times, we can talk legitimately about the influence not of humors, but of hormones on temperament. Thus, in ancient times, a preponderance of blood was said to lead to a sanguine or enthusiastic temperament; the sadness of the melancholic was attributed to an excess of black bile; an over-abundance of yellow bile produced the irritability of the choleric; and finally, the slowness and apathy of the phlegmatic was due to the influence of phlegm. Since the humors were thought to leave their mark on the body, particularly the face, each type could be recognized by its characteristic physiognomy [18].

Individual differences refer to between-person variations in behavior. In this context, "behavior" may be construed narrowly in terms of a single domain of psychological activity, or it may be defined broadly to include cognition, affect, motivation, overt action, and neurobiological activity. Personality psychologists do not share a single view of the nature of individual differences per se, or of the importance of any one domain of individual differences in particular. Moreover, not all individual differences involve personality. Nonetheless, in a general sense, personality and the study of individual differences are intimately related.

The relevance of individual difference dimensions to the development and course of physical health problems depends on their association with mechanisms involved in the etiology and pathogenesis of disease, or with processes that affect the detection, control, and outcome of physical disorders. A rather wide range of individual difference constructs have been implicated as possible risk factors for physical illness. The field is narrowed, somewhat, when it is limited to those areas of individual differences that involve personality [19]. 
One of the major dimensions of personality in current focus is the big five personality. Personality researchers have proposed that there are five basic dimensions of personality. Evidence of this theory has been growing over the past 50 years, beginning with the research of Fiske [20] and later expanded upon by other researchers including, Goldberg [21] and McCrae \& Costa [22].

The "big five" are broad categories of personality traits. While there is a significant body of literature supporting this five-factor model of personality, researchers don't always agree on the exact labels for each dimension. However, these five categories are usually described as follows:

1. Extraversion: This trait includes characteristics such as excitability, sociability, talkativeness, assertiveness, and high amounts of emotional expressiveness.

2. Agreeableness: This personality dimension includes attributes such as trust, altruism, kindness, affection, and other prosocial behaviors.

3. Conscientiousness: Common features of this dimension include high levels of thoughtfulness, with good impulse control and goal-directed behaviors. Those high in conscientiousness tend to be organized and mindful of details.

4. Neuroticism: Individuals high in this trait tend to experience emotional instability, anxiety, moodiness irritability, and sadness.

5. Openness: This trait features characteristics such as imagination and insight, and those high in this trait also tend to have a broad range of interests.

These dimensions represent broad areas of personality. Research has demonstrated that these groupings of characteristics tend to occur together in many people. For example, individuals who are sociable tend to be talkative. However, these traits do not always occur together. Personality is a complex and varied and each person may display behaviors across several of these dimensions.

Starting from widely differing standpoints, Eysenck, and McCrae and Costa have produced virtually identical models of personality [22,23]. In Eysenck's case, his early work with traumatized servicemen immediately after World War II was followed by more extensive research with a variety of clinical populations and, increasingly, a massive experimental research effort. McCrae and Costa, on the other hand, base their model on factor analytic studies of personality descriptions in ordinary language. In both cases, the authors have converged on a threedimensional model of personality comprising: Neuroticism (negative emotionality), Extraversion (positive emotionality), and a third dimension referred to by Eysenck as "Psychoticism" and by McCrae and Costa as "Openness to Experience". Although Eysenck believes Psychoticism and Openness to be opposite poles of the same dimension, McCrae and Costa demur, arguing that the link remains to be demonstrated [23].

\section{Type A and Type B personality}

The Type A behaviour pattern is an observable set of behaviours or style of life characterized by extremes of hostility, competitiveness, hurry, impatience, restlessness, aggressiveness (sometimes stringently suppressed), explosiveness of speech, and a high state of alertness accompanied by muscular tension. People with strong Type A behaviour struggle against the pressure of time and the challenge of responsibility [24]. Type A is neither an external stressor nor a response of strain or discomfort. It is more like a style of coping. At the other end of this bipolar continuum, Type B persons are more relaxed, cooperative, steady in their pace of activity, and appear more satisfied with their daily lives and the people around them.

The Type A/B behavioural continuum was first conceptualized and labelled in 1959 by the cardiologists Dr. Friedman and Dr. Rosenman [25]. They identified Type A as being typical of their younger male patients with Ischaemic Heart Disease (IHD).

The intensity and frequency of Type A behaviour increases as societies become more industrialized, competitive and hurried. Type A behaviour is more frequent in urban than rural areas, in managerial and sales occupations than among technical workers, skilled craftsmen or artists, and in businesswomen than in housewives.

Type A persons are generally competitive, achievementorientated, time urgency and easily aroused to anger, which may be overt or covert. Several theoretical mechanisms potentially link Type A Personality to burnout. First, Type A individuals are likely to perceive the work environment negatively, independent of the objective nature of one's job due to the individual self-appraisal resulting from the person's unique personality trait. For example, due to their tendency to become easily angry, Type A individuals may perceive even minor or accidental slights as major injustices. Furthermore Type A individuals are likely to evoke negative responses from co-workers [26], to manipulate their jobs in ways that produce stressors [27] and they may self-select into jobs that are inherently stressful [28]. Type A personality has been found to moderate negatively the effects of stress. An individual with type A personality is believed to be more vulnerable to stress and stress related problems than type B individual.

The concept of personality types can be defined as the psychological classification of people on the basis of their personality traits. Type A and Type B personality theory, which proclaims that type A people are those who are very achievement-oriented, impatient, business like, ambitious, competitive, and status conscious, while type B people are patient, easy-going and relaxed, is based on this concept itself

According to Mosby's Dental Dictionary [29], Type B personality is described as an "ego state characterized by a form of behavior associated by Friedman and Rosenman with people who appear free of hostility and aggression and who lack a compulsion to meet deadlines, are not highly competitive at 
work and play, and have a lower risk of heart attack".

The type B personality has sometimes been characterized as the type A's polar opposite, utilizing more negotiation and alliance-building in gaining support for their positions, having a more easy-going, less demand-driven psyche, better able to relax and to experience happiness through many different kinds of experiences, rather than just the goal driven experience. Type B's have often been characterized as calming personalities, naturally able to draw down stress in interpersonal transactions and organizations. They have been identified as physiologically more likely to live longer, healthier lives, whether due to more moderated activation of stress hormones or less physiologically activated in fight or flight mode save for when necessary [30].

\section{Stress and personality}

The link between personality and stress was discovered in the early 1960's by Meyer Friedman and Ray Rosenman, two American cardiologists. They discovered a set of behaviours that seemed to characterise people at risk from heart disease and termed these Type A behaviours. Type A individuals tend to:- Accentuate various key words in ordinary speech without real need and tend to utter the last few words of sentences far more rapidly than the opening words. They tend to finish other people's sentences for them. Always move, walk and eat more rapidly. Feel impatient about the rate at which most events take place. Attempt to do several things at once, for example driving and dictating at the same time, thinking about another subject while someone else is talking to them, signing letters while talking to someone on the phone and so on. They find it hard to talk about things which do not have a personal interest and may feel guilty when trying to relax. Try to schedule more into less and less time, making few allowances for unforeseen events. Have a persistent sense of time urgency, and often condition to the minute how long their regular journeys take them.

There is therefore some evidence to suggest that physiological reactions to stress are different between individuals: some are highly reactive, and some are less reactive. For instance, heart rate responses are exaggerated in people who are stress prone [10]. The strength of the reaction, however, does vary depending on how stressful the event is judged to be [4]. This clearly indicates that the cognitive appraisal of the same event may be quite different in two people. For example, a person who is afraid of flying may consider going on a far-flung holiday to be extremely stressful, whereas a person who likes flying may consider the holiday travelling to be much less stressful. In addition, physiological responses to the same stressor (which may be either a physical or mental stressor) differ across individuals [31]. That is, the biological stress response itself reflects multiple dimensions of individual differences, at least some of which dimensions are closely related both to personality and cognitive appraisal mechanisms.

That the experience of stress has undesirable influences, both on the health and safety of individuals and on the effectiveness of the community or organization to which they belong has been well known and admitted belief for a long time now.

\section{Stress and gender}

It is not known for sure if stress affects men and women differently. Generally, as the two genders often operate in different social contexts, both tend to develop different emotional dispositions and personality traits. Accordingly, their responses and coping mechanisms to stress situations vary.

Women, in these days, have a lot of balancing to do between home and workplace, including balancing between social and personal requirements. The issues of maternity, menopause, parenthood, gender roles, conditions at home and workplace, familial and social support et al, often blight women's lives in the long run.

Sociological researches assert that family structure (working or stay-at-home mothers and other models) affects performance and employee attendance either directly or interactively. Family demands and family attitudes were found to influence the absence frequency at workplaces.

Experiencing a high level of burnout was associated with increased absenteeism if employees had children under 6 living at home or reported having difficulty with their child care arrangements. There is a strong relationship between social support and mental stress and trauma in women. It relates to a woman's help-seeking attitude, social networks, kinship networks, and support networks. Besides these factors adapting to a new workplace culture and reformations tends in job sectors, affects men and women alike.

Quantity and quality of leisure time distribution between the genders is an interesting index of how women get burdened with stress for either natural or social obligations. Multinational Time Budget Data Archive and the Australian Time Use Survey suggest that women are now bearing a "dual burden" as both family providers and family careers. Although men and women have similar quantities of free time, when the character of leisure is considered the gap between genders reemerges. Absence of reciprocal and joint emotion management within family is a nagging stressor for women. Mostly mothers handle the bulk of the parental responsibility such as educational and emotional care of children. This can be both physically and psychologically draining.

Much of the stress men go through arises from their self nurtured identities, especially related to their professional status. "If you ask a man who he is, the first thing he says is his work-I'm an executive, I'm a doctor, I'm a house-builder," says Glenn E. Good, an associate professor of educational and counseling psychology at the University of Missouri, Columbia. "Suppressing feelings and internalizing stress are acquired male traits", says Good, "On some inner level, it comes down to: If I can't tough it out, then I'm not much of man." The nature of Job and Stress for men workplace stress can have extreme consequences. In Japan, job-stress related suicide 
rate among men has risen over the last 15 years. According to the Government's Statistics Bureau, the highest suicide rate occurs in men from 35 to 44 years old, making it the 13th most common cause of death for men. Newspapers carried the triple suicide story in March 1998, when three Japanese men-all heads of car part companies-took their lives on the same night. The reason they gave is-Poor Company Finances! Uncertainty in workplace can cause high levels of stress. Lack of information or the actions of other people can negatively affect your ability to perform.

In the face of a stressful experience, women are more likely than men to say they feel anxious, which may lead to risk for depression and anxiety disorders. Men are more likely than women to use alcohol to fight stress. This could lead to alcohol use disorders.

Admittedly, women most often than men tend to focus on negative emotional aspects of stressful circumstances. In contra-distinction, men tend to distract themselves from negative emotions, to try not to think about these emotions. The difference in coping styles in men and women could simply be as a result of their different personality styles. But it might as well be as a result of their different genders.

Researchers from UCLA analyzed data from hundreds of biological and behavioural studies (both human and animals), and concluded that females were more likely to deal with stress by "tending and befriending"-that is nurturing those around them and reaching out to others. Men on the other hand, were more likely to sequester themselves or initiate a confrontation behavior with the "fight or flight" response that has long been associated with stress.

The difference in men and women in reaction to stress items might be more than just an interesting observation. It could account for differences in their longevity and health. From observation women enjoy a greater life expectancy than men. The possible explanation is that the "tend and befriend" system protect women from some of the damaging effects of stress.

Again oxytocin, a hormone that promoted both material and social behavior and enhances relaxation could equally bring about the difference. When in the face of stress, the body releases a number of different hormones. Some of these hormones, especially cortisol and adrenaline, raises blood pressure and cholesterol levels and suppress the immune system, putting often stressed people at greater risk for everything from colds to cancer or heart disease. Some research also suggests that constant, long-term exposure to stress can lead to weight gain thanks to elevated cortisol levels. At on set, women have the same response to stress as men, leaving them somewhat vulnerable to cortisol and adrenaline. But then women also begin secreting oxytocin from the pituitary gland, which helps scale down the production of cortisol and adrenaline, minimizing their harmful effects.

\section{Stress and personality}

In a general sense, a type is a group or category of things distinguished by the common characteristics of its members. A personality type, therefore, is a category of people who exhibit a particular combination of psychological characteristics, the assumption being that this combination is unique and distinguishes the type from others [18].

Besides the perceived differences based on gender in the manifestation of stress response, there is some evidence to suggest that physiological reactions to stress are different between individuals: some are highly reactive, and some are less reactive. For instance, heart rate responses are exaggerated in people who are stress prone [10]. The strength of the reaction, however, does vary depending on how stressful the event is judged to be [4]. This clearly indicates that the cognitive appraisal of the same event may be quite different in two people. For example, a person who is afraid of flying may consider going on a far-flung holiday to be extremely stressful, whereas a person who likes flying may consider the holiday travelling to be much less stressful. In addition, physiological responses to the same stressor (which may be either a physical or mental stressor) differ across individuals [31]. That is, the biological stress response itself reflects multiple dimensions of individual differences, at least some of which dimensions are closely related both to personality and cognitive appraisal mechanisms.

Some researchers have found that individual differences in physiological reactivity to stress are stable over time: people who have exaggerated responses on one occasion are likely to do so on other occasions. In a second study using video games as the stressor, heart-rate reactions were found to be stable between the baseline task and the same task given again, twenty months later [32]. Other studies have demonstrated that there is differential stress hormone release (cortisol) in subjects subjected to a mental stress in the laboratory [33] which is stable across tasks. Low stress hormone reactors remained low, and high reactors remained high, across the tasks.

In addition to studies of the physiological stress response, personality and cognitive predictors of stress proneness in individuals have been widely researched-and have been greatly facilitated by the resurgence of the two broad personality type theory or trait theory, and psychometrically sound measures of traits.

\section{Methods}

\section{Study design}

This was a cross-sectional descriptive study of 18 public Secondary schools teachers in Aguata and Anaocha Local Government Councils of Anambra State Nigeria.

\section{Study setting}

The study was carried out in public Secondary schools teachers in Aguata and Anaocha Local Government Councils of Anambra State Nigeria among the Secondary School teachers.

\section{Study population and sampling strategy}

38 males (18 type A and 20 type B persons); and 52 females (27 type A and 25 type B persons), were selected from 18 public Secondary schools in Aguata and Anaocha Local Government Councils of Anambra State Nigeria, (90 participants were recruited for the study. 


\section{Data collection}

Public Secondary schools teachers in Aguata and Anaocha Local Government Councils of Anambra State Nigeria were selected for the study. Informed consent to take part in the study was obtained before questionnaires were administered to each participant. In collaboration with school principals 90 participants were recruited for the study.

Jenkins Activity Survey Scale (Jas), Symptom Distress Checklist (SCL-90) and a sociodemographic questionnaire were used to collect data. The sociodemographic questionnaire gave information about the participant's age, employment status, educational attainment, parity, gestational age, obstetric history and knowledge and treatment of anxiety and depression.

The instrument was formulated by Jenkins, Zyzanski \& Rosenman [24] and used in Nigeria by Erinoso [34], Onighaiye [35]. It was modified at Framingham Heart Study (USA), and reduced to ten-item questionnaire shown to be a valid predictor of future ischaemic heart disease (IHD) for both men and women. It was then called The Framingham Type A Scale (FTAS). It has also been used internationally both in cardiovascular and psychological research. The instrument was designed for both normal and clinical adult population.

The questionnaire consists of ten (10) questions to which respondent answers "A to C" options to choose the one that best describes his/her reactions.

Maximum A's mean your personality type is ' $A$ ', maximum ' $B$ 's mean you are a mixed personality i.e. $A B$ and maximum ' $C$ 's mean you are type B personality. Only those who manifested maximum ' $\mathrm{A}$ 's and ' $\mathrm{C}$ 's were used for further research.

\section{Symptom distress checklist (Scl-90)}

This was formulated by Derogatis, Lipman and Covi [15]. The test was designed to measure several manifestations of distress. It is a 90 item inventory designed to assess 10 primary categories of symptoms associated with distress. The researcher modified this original instrument by selecting only five of the ten categories which deals more with emotional stress. The modification therefore was only as regards reduction of items and subscales. The five categories contain 44 items.

\section{The 5 categories are:}

i. Somatization: Bodily pain, discomfort \& dysfunction, items 1-12.

ii. Interpersonal Sensitivity: Discomfort in social situations, items 13-21.

iii. Anxiety: Restlessness, Nervousness and Tension, items 22-31.

iv. Hostility: Feeling of anger, hatred, repression and unfriendliness, items 32-37.

v. Phobia: Irrational fear and avoidance of objects, places and situations, items 38-44.

The Sections I-V was scored separately. The values of the numbers shaded in each item in each section should be added to obtain the score. The scores for all the section were added together to obtain the overall score. Participants were required to respond to the items on how much that problem bothered or distressed them in the recent past, including today. Thus the items were worded positively as: (0) Not at all, (1) A little bit, (2) Moderately, (3) Quite a bit, and (4) Extremely. However, the Nigerian mean score was the basis for interpreting the scores of clients. Scores higher than the mean score, indicates that the participant manifests the characteristics of the particular SCL-90 scale.

A concurrent validity of 0.47 was obtained by Erinoso [34] and an alpha coefficient of 0.77 and a test retest reliability coefficient of 0.90 were obtained by Derogatis [36].

\section{Data analysis}

Data obtained were analysed using SPSS version 16 . The frequency distribution of the variables was calculated.

\section{Ethical consideration}

Approval to conduct this study was obtained from the principals of the school involved.

\section{Study population}

A total of 90 participants teaching in the public secondary school in Aguata and Aniocha Local Government Councils Anambra State were studied.

\section{Sociodemographic characteristics}

The participants were within the age range of 24 to 54 years with mean age of 34.7 years, and a standard deviation of 7 years. The 52 female participants were within the age range of 24 to 54 years, with mean age of 35.4. On the other hand, the 38 male participants were within the age range of 26 to 52, with mean age of 34.7. 41 of the participants held National Certificate in Education (NCE) or its equivalent, as their qualification; while 49 had first degree, its equivalent HND and above as their teaching qualification.

\section{Discussion}

Two hypotheses in this study yielded significant outcomes. However, the first hypotheses, which stated that "there will be no significant effect of personality types on emotional stress manifestation", was rejected. This means that a significant effect of type A and type B personalities in stress reaction was observed among the participants. In other words, type A people and type B people differ significantly in stress manifestation. The outcome of the finding revealed that type A persons tend to be more stressed up than type B persons in response to stress items. One could say that the reason for this may be attributed to the fact that, individuals with type A personality tend to be action-oriented, rush to complete things, and are overly ambitious, tremendously, the most major trait of the Type A man is his consistent sense of time urgency.

This finding therefore agrees with similar study by [37], in which he stated that Type A traits can essentially be divided into impatience, aggression and competitiveness. Within 
each we see particular displays of behaviour. Being impatient means the Type A85 will get irritated by delays and people they consider incompetent. They will demand people to hurry up. They are unable to relax and to take time out and sit quietly doing nothing. Everything is a rush to the Type A, no matter what it is. As such, they are adept at multitasking.

The Type A Personality is prone to anger. They will become hostile to people who do not meet their high expectations. Winning is all important and the Type A will compete no matter who it is against. Recognition and advancement is very important and they will push themselves to their limits to try and achieve as much as possible, as quickly as possible. However, the Type A may feel unfulfilled as they constantly want to achieve more and more and sometimes their goals may not be realistic. Although they may appear confident, the Type A may suffer from self-doubt. These characteristics of the Type A Personality means they will be susceptible to greater stress and as such will be at risk of the associated problems. Given the very nature of the Type A Personality it is somewhat not surprising that it has associated health risks. Studies suggest that coronary heart disease, blood clots and high cholesterol are health risks to people with a Type A Personality. It is possible that they are also more likely to suffer a heart attack [35]. In another study, the extent to which interpersonal dependency and its indicators such as emotional reliance, lack of self-confidence and assertion of autonomy could predict psychological distress. 300 staff of Lagos University Teaching Hospital (LUTH) and College of Medicine, University of Lagos was participants. Interpersonal Dependency Inventory (IDI) and Symptom Distress Checklist 90 (SCL-90) were administered concurrently to them. Analyzing the data with one-way analysis of variance (ANOVA) and multiple regression, it was found that highly dependent individuals manifest higher levels of psychological distress specifically, interpersonal sensitivity, obsessive-compulsive, depression, anxiety, hostility, paranoid ideation and neuroticism $(\mathrm{P}<5, \mathrm{df}=2 / 147$, critical $\mathrm{F}=3.06$ ). In addition, lack of self-confidence was found to predict significantly psychological distress. The results were discussed in the light of the need to address personality issues and institute intervention for them towards developing a saner society [38-43].

The second hypothesis which stated that "Males and females will not differ in their response to emotional stress" was however upheld as there was no significant effect discovered between male and female in their response to emotional stressful experience. Though this finding goes contrary to popular expectations, most of the studies in this area came from the western world, with little reference to our culture. The recent drastic shift in our value system, putting more responsibility on women as both co-bread winners and housekeepers, could also account for increased reaction to stress stimuli as men.

The third hypothesis stating that: "there will be no interactive effect between gender and type $A$ and $B$ persons in their reaction to emotional stressful life experience", was the second hypothesis to yield a significant outcome. The Ho hypothesis was therefore rejected because there was significant interactive effect between gender and type $\mathrm{A}$ and $\mathrm{B}$ persons in their reaction to emotional stressful life experience. The implication is that personality type and gender plays significant role in the participants' reaction to stress stimuli.

\section{Limitations of the study}

The findings of this study have some limitations, ranging from the number of participants to the attitude of the sample. Only ninety participants were used out of over $140,000,000$ in Nigeria. Secondly, the number of males who participated in this research is small in relation to that of female; this is because the population of female teachers outnumbered that of their male counterparts in the area covered by the researcher.

Some of the participants felt disturbed at the initial stage thereby refusing to co-operate but this was later overcome with the establishment of rapport and confidentially by the researcher.

Lack of adequate funding also made it impossible for the researcher to widen the scope of the research to include other areas.

\section{Conclusion}

Based on the outcome of this study, the researcher hereby concludes that personality Type as a factor yielded a significant effect in manifestation of emotional stress. Gender however did not significantly affect manifestation of emotional stress. On the other hand it was shown that there is interactive effect between gender and personality type in emotional stress reaction to noxious life experiences.

\section{Acknowledgements}

We acknowledge the support received from all the principals of the schools studied, Prof Amaechi Nweze in the review of the initial draft and supply of articles that helped us in the literature review.

\section{Competing interests}

The authors declare that they have no financial or personal relationship(s) that may have inappropriately affected their report of the findings of this research.

\section{Author's contributions}

O.C. F conceived the topic and performed the literature search. P.C.O. conducted the results analysis and wrote the discussion $\mathrm{O}$. M O was involved with collecting the data and entering them into SPSS.

\section{References}

1. Nweze A (1984) Executive Stress and its Management. The Nigerian Manager: Challenges and Opportunities, Longman Nigeria.

2. Isichei A (2000) Posttraumatic stress disorder. N Engl J Med 346: 108-114. Link: http://bit.ly/35TEjZg

3. Colman AM (2003) Oxford Dictionary of psychology. Oxford University press 
Inc New York

4. Sarafino E (2002) Health Psychology: biopsychosocial interactions (4 $4^{\text {th }} \mathrm{Ed}$ ) New York , NY USA John Wiley and Sons Inc. Link: http://bit.ly/391Gr30

5. Baum A (1990) Stress, instrusive imagery, and chronic distress. Health Psychol 9: 653-675. Link: http://bit.ly/350eZ6V

6. Lazarus R, Cohen J (1977) Environmental stress. Hum Behav Environ 89-127. Link: http://bit.ly/2MolEMk

7. Cox T (1978) Stress. Macmillian, London 24: 322. Link: http://bit.ly/2Qe3XRU

8. Lazarus W, Folkman M (1984) Conquer your stress. London.

9. Lazarus R (1999) Stress and emotion: Anew synthesis. New York Springer Publishing Co. Link: http://bit.ly/2Qj8ra1

10. Carroll D (1992) Health psychology: stress, social support, and the buffering hypothesis. Psychological bulletin, 98310-357

11. Selye H (1956) Stress of life. MMcGrew-Hill, New York. Link: http://bit ly/372mVSe

12. Rahe RH, Mahan JL, Arthur RJ (1970) Prediction of near future health change from a subjects preceding life change. J Psychosom Res 14: 401-406. Link: http://bit.ly/2ZmO6Ex

13. Friedman M, Rosenman R (1974) Type A behaviour and your heart. New York: Knopf. Link: https://amzn.to/2QgsnKA

14. Deary MG I, Whiteman MC (2009) Personality Traits ( $3^{\text {rd }}$ Ed) Cambridge University Press. Link: http://bit.ly/397Lr6n

15. Kavanagh T, Shephard RJ (1973) The Immediate Antecedents of Myocardial Infarction in active men. Can Med Assoc J 109: 19-22. Link: http://bit.ly/2MkkylV

16. Selye H (1946) The General Adaptation Syndrome and the disease of Adaptation. J Clin Endocrinol Metab 6: 117. Link: http://bit.ly/2tIBOut

17. Segal J (2010) The Language of Emotional Intelligence. Link: http://bit.ly/2tLciEZ

18. Miller A (1991) Personality Types: A Modern Synthesis, Alta University of Calgary Press. Link: http://bit.ly/2Qeb6Se

19. Baum A, Revenson TA, Singer JE (1997) Handbook of Health Psychology. Lawrence Erlbaum Associates, New Jersey

20. Fiske D (1949) Consistency of the factorial structure of personality ratings from different sources. J Abnorm Psychol 44: 329-344. Link: http://bit.ly/2Smg0zb

21. Goldberg LR (1981) Language and individual differences: The search foruniversal in personality lexicons. In $\mathrm{L}$ Wheeler (Ed). Review of personality and social psychology Hillsdale, NJ Eribaum 2: 141-165. Link: http://bit.ly/35TMAwi

22. McCrae R, Costa P (1987) Validation of the five-factor model of personality across instruments and observers. J Pers Soc Psychol 52: 81-90. Link: http://bit.ly/2Qf4e6X

23. Eysenck H, Eysenck M (1985) Personality and individual differences. New York: Plenum. Link: http://bit.ly/2EQNoWY

24. Jenkins CD, Zyzanski S, Rosenman RH (1979) Manual for the Jenkins Activity Survey. New York: Psychological Corp. Link: http://bit.ly/2SobekW
25. Friedman M, Roseman S (1974) Affects on performance resulting from variations in stress levels occurring during evaluations. Journal of the South western society of Economists 17: 73-77.

26. Spector PE, O’Connell B (1994) The contribution of personality traits, negative affectivity, locus of control and Type $A$ to the subsequent reports of job stressors and job strains. Journal of Occupational Psychology 67: 1-11. Link: http://bit.ly/2QfofdJ

27. Caplan R, Jones K (1975) Effects of work load, role ambiguity, and Type A personality on anxiety, depression, and heart rate. J Appl Psychol 60: 713-719. Link: http://bit.ly/2MoGDzO

28. Burke RJ, Deszca E (1982) Preferred organizational climates of Type A Individuals. Journal of Vocational Behaviour 21: 50-59. Link: http://bit.ly/34TJilb

29. (2008) Mosby's Dental Dictionary. $2^{\text {nd }}$ edition. Elsevier, Inc.

30. David J (2005) Psychology of Stereotyping. Guildford Press, New York. Link: Link: http://bit.ly/2PUmZO0

31. Marsland AL, Cohen S, Rabin BS, Manuck SB (2001) Associations between stress, traits, negative affects, acute immune reactivity, and antibody response to hepatitis B inject in healthy ypong adults. Health Psychol 20: 4-11. Link: http://bit.ly/2PRbMhq

32. Turner $J$ (1986) The significance of the social identity concept for social psychology. Br J Soc Psycho 25: 231-252. Link: http://bit.ly/37bk61r

33. Roy M, Kirschbaum C, Steptoe A (2001) Psychological, cariovscular, and metabolic correlates of individual differences in cortisol stress recovery in young men. Psychoneuroendecrinilogy 26: 375-391. Link: http://bit.ly/2Mq1brL

34. Erinoso O (1996) The Sources of Stress among Nigerian retirees. Unpublished B.Sc Thesis, Department of Psychology, University of Lagos.

35. Onighaiye M (1996) The impact of length of time on the University on ego identity. self-esteem and stress manifestation in students. Unpublished B.Sc Thesis. Psychology Department University of Lagos.

36. Derogatis L, Lipman R, Cori L (1977) SCL-90R: administration, scoring and procedures manual. Baltimore: John Hopkins University Schol of Medicine Clinical Psychometric Research Unit.

37. Barnard (2007) Type A behaviour pattern: A new insight to gender challenges in higher education. dimensions of health and sickness, Tavistock Publications Ltd; Great Britain.

38. Umeh C (2009) Interpersonal Dependency: A Predictor of Psychological Distress.

39. Bakal DA (1979) Psychology and Medicine: Psychobiological.

40. Lundberg B (1996) The Psychology of optimal Experience. Harper Collins, New York.

41. McCrae RR, Costa PT (1989) The structure of interpersonal traits. Wiggin's circumplex and the five-factor model. J Pers Soc Psychol 56: 586-595. Link: http://bit.ly/2ELhXNL

42. Norman w (1967) 2,88 personality traits descriptive: Normative operating characteristics for a university population. Ann Arbor: University of Michigan, Department o psychology.

43. Smith BB (1967) Contemporary psychology Experiments: Adaptations for Laboratory. Link: http://bit.ly/34RLsI7

Copyright: (C) 2019 Ofojebe CP, et al. This is an open-access article distributed under the terms of the Creative Commons Attribution License, which permits unrestricted use, distribution, and reproduction in any medium, provided the original author and source are credited.

Citation: Ofojebe CP, Okoli PC, Okemefuna OM (2019) The role of gender and personality (Type "A" and "B"); on emotional stressful experience. Ann Alzheimers Dement Care 3(1): 011-019. DOI: https://dx.doi.org/10.17352/aadc.000008 